\title{
Peak inspiratory flow: measurement using a modified mini Wright peak
}

\section{flow meter}

\author{
MH DEPLEDGE
}

From the Department of Physiology, Faculty of Medicine, University of Hong Kong, Hong Kong

\begin{abstract}
A simple and inexpensive modification of the miniature Wright peak flowmeter is described which permits measurement of peak inspiratory flow (PIF) while retaining the capability to measure peak expiratory flow (PEF).

The device is shown in the figure. A miniature Wright peak flowmeter ${ }^{1}$ is housed in a perspex cylinder of internal diameter $10 \mathrm{~cm}$ and internal length $16 \mathrm{~cm}$. The outer surface of the flowmeter's tapered mouthpiece socket forms a tight seal with the cylinder lid, so that when assembled the flowmeter protrudes into the cylinders' interior (fig). A second socket (3 cm diameter) in the base of the cylinder holds the mouthpiece used in inspiratory manoeuvres. The device weighs about $625 \mathrm{~g}$.
\end{abstract}

\section{Principle of operation}

During a forced inspiration air is evacuated from the cylinder but is rapidly replaced by air rushing in through the flowmeter inlet. Inspiratory rate is therefore equivalent to the rate of airflow into the cylinder and can be read off the flowmeter scale.

The risk of cross infection among patients performing inspiratory manoeuvres using the same piece of equipment is considerable. ${ }^{2}$ It is therefore recommended that the mini Wright flowmeter is sterilised after use by following the procedures described in the instructions supplied with the instrument. The perspex cylinder can be rendered aseptic by washing it in a solution of $0.5 \%$ chlorhexidine in alcohol.

\section{Evaluation of measurements}

To be of clinical use the device must give accurate and reproducible estimates of PEF and PIF. Verification was first obtained that enclosure of the flowmeter did not affect its flow characteristics.

Twenty seven volunteers were asked to perform four forced expiratory manoeuvres while seated and with their nostrils occluded. In the first and third tests PEF was measured conventionally while in the second and fourth tests the cylinder was assembled around the flowmeter. The mean (SD) difference between values obtained normally and with the cylinder in position was $4 \cdot 1(15 \cdot 1)$ litres

Address for reprint requests: Dr MH Depledge, Department of Physiology, University of Hong Kong, Li Shu Fan Building, Sassoon Road, Hong Kong.

Accepted 8 September 1984 $\min ^{-1}$ It was concluded that the cylinder did not impair airflow and that the values recorded on the scale accurately reflected the maximum air pressure differences across the flowmeter diaphragm whether or not the device was being used to measure expiratory or inspiratory flow.

A larger series of volunteers were asked to perform expiratory and inspiratory manoeuvres to provide estimates of PEF, PIF, and PEF/PIF ratio for comparison with published data. The test subjects were healthy, nonsmoking, male and female Chinese medical students (55 in all). PEF was measured normally with the miniature Wright flowmeter. Then the subject was asked to perform a maximal expiration into room air before going on to the mouthpiece to attempt a maximal inspiratory manoeuvre using the modified device. Close attention was paid to the correct performance of the tests. Usually the result of the better of two attempts was recorded but in a few cases four or five attempts were required before the manoeuvres were mastered successfully. The results are summarised in the table. Values were consistent with those that have been reported previously. ${ }^{3-6}$ It was therefore concluded that reliable estimates of PEF and PIF had been obtained.

\section{Discussion}

Objective evaluation of the extent of respiratory impair-

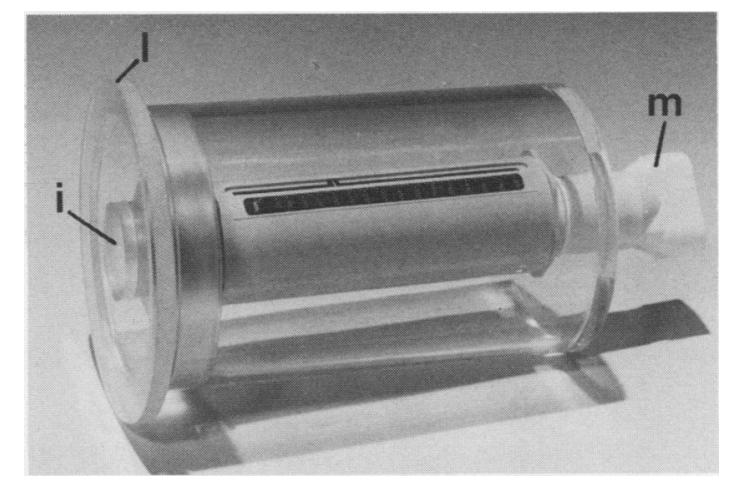

Modification of the Wright mini peak flowmeter for the measurement of peak inspiratory flow. The photograph shows the meter enclosed within the perspex cylinder. The mouthpiece $(m)$ connects with the interior of the cylinder and is used for inspiratory measurement. The peak flowmeter inlet (i) is secured to the lid (1) of the cylinder and is in contact with the outside air. 
Peak expiratory flow (PEF), peak inspiratory flow (PIF), and PEF/PIF ratios (means with standard errors in parentheses) measured with the modified flowmeter

\begin{tabular}{|c|c|c|c|}
\hline Details of subjects & $\begin{array}{l}P E F \\
\left(l \text { min }^{-1}\right)\end{array}$ & $\begin{array}{l}P I F \\
\left(l \text { min }^{-1}\right)\end{array}$ & $\begin{array}{l}P E F / P I F \\
\text { ratio }\end{array}$ \\
\hline $\begin{array}{l}\text { Men }(n=36) \\
\text { Age 19-22 y } \\
\text { Height } 163-186 \mathrm{~cm} \\
\text { Women }(\mathrm{n}=19) \\
\text { Age 18-21 y } \\
\text { Height 152-171 cm }\end{array}$ & $524 \cdot 3(55 \cdot 9)$ & $365 \cdot 7(75 \cdot 9)$ & $1 \cdot 48(0 \cdot 27)$ \\
\hline
\end{tabular}

ment in patients with lung disease is extremely difficult without recourse to extensive testing in a lung function laboratory. Many attempts have, however, been made to overcome this difficulty by using a single test, the most successful having been the measurement of PEF. ${ }^{78}$ Surprisingly, measurement of PIF and PEF/PIF ratio has seldom been attempted despite the proved value of these indices in the quantitative assessment of airways obstruction in asthma $^{6}$ and vocal cord paralysis, ${ }^{9}$ the severity of dyspnoea, ${ }^{3}$ and the effectiveness of bronchodilator drugs. ${ }^{10}$

The modification to the miniature Wright peak flowmeter described above provides a simple, inexpensive, and reliable method of measuring PEF, PIF, and PEF/PIF ratio. The device is robust and easy to use, and can be rendered aseptic by simple decontamination procedures.

\section{References}

1 Wright BM. A miniature Wright peak flow meter. $\mathrm{Br}$ Med J 1978;ii: $1627-8$.

2 Depledge MH, Barrett A. Aseptic techniques for lung function testing. J Hosp Infect 1981;2:369-72.

3 McNeill RS, Malcolm, CD, Rhind Brown W. A comparison of expiratory and inspiratory flow rates in health and in chronic pulmonary disease Thorax 1959;14:225-31.

4 March HW, Lyons HA. A study of the maximal ventilatory flow rates in health and disease. Dis Chest 1960;37:602-14.

5 Butler J, Caro CG, Alcala R, DuBois AB. Physiological factors affecting airway resistance in normal subjects and in patients with obstructive respiratory disease. $J$ Clin Invest 1960;39:584-91.

6 Nairn JR, McNeill RS. Adaptation of the Wright peak flow meter to measure inspiratory flow. Br Med J 1963;i:1321-3.

7 Ward FG. Practical pulmonary function testing. J Soc Occup Med 1977;27:138-42.

8 Haydu SP, Chapman TT, Hughes DTD. Pulmonary monitor for assessment of airways obstruction. Lancet 1976;ii:1225-6.

9 Miller RD, Hyatt RE. Evaluation of obstructing lesions of the trachea and larynx by flow-volume loops. Am Rev Respir Dis 1973; 108:475-81.

10 Saunders KB. Bronchodilator response patterns in patients with chronic airways obstruction: use of peak inspiratory flow rate. $\mathrm{Br}$ Med J 1967;ii:399-402. 